\title{
OS SIGNIFICADOS DAS ATIVIDADES DA CULTURA CORPORAL E OS OBJETOS DE ENSINO DA EDUCAÇÃO FÍSICA
}

\author{
THE MEANINGS OF BODILY CULTURE ACTIVITIES AND PHYSICAL \\ EDUCATION'S TEACHING OBJECTS
}

\section{LOS SIGNIFICADOS DE LAS ACTIVIDADES DE LA CULTURA CORPORAL Y LOS OBJETOS DE ENSEÑANZA DE LA EDUCACIÓN FÍSICA}

\section{Carolina Picchetti Nascimento*}

Palavras chave: Educação Física. Ensino.

Cultura.

Conhecimento.
Resumo: Discuto neste ensaio uma conceituação sobre os objetos de ensino da Educação Física a partir da sistematização dos significados das atividades da cultura corporal. Assumindo a dança como um exemplar para a análise, apresento alguns critérios teóricometodológicos para a proposição dos significados da cultura corporal em uma perspectiva histórico-cultural. Considerando que essas atividades possuem uma dimensão autônoma (o que não quer dizer independente) das determinações sociais de gênero, classe, etnia etc., destaco como eixo dessa sistematização aquelas características relacionadas à singularidade formativa, ou ao "fazer criador", que a dança, o jogo, a luta e a ginástica têm ou podem vir a ter para os sujeitos que ensinam e aprendem tais atividades na escola.
Keywords:

Physical Education. Teaching.

Culture.

Knowledge.
Abstract: This essay discusses a concept about Physical Education's teaching objects based on the systematization of the meanings of bodily culture activities. Taking "dance" as an example for analysis, I present some theoretical and methodological criteria for meanings of bodily culture from a Cultural-Historical perspective. Considering that these activities have an autonomous dimension - which does not mean they are independent - regarding social relations of gender, class, ethnicity etc., as the center of this systematization, I point out those features related to formative singularities, or "creative making", which "dance", "play", "fight" and "gymnastics" have or may have regarding the subjects who teach and learn them at school.

Resumen: Discuto en este ensayo una conceptualización de los "objetos de enseñanza" de la Educación Física a partir de la sistematización de los significados de la cultura corporal. Asumiendo la "danza" como un ejemplar para el análisis, presento algunos criterios teórico metodológicos para la proposición de los significados de la cultura corporal en una perspectiva Histórico Cultural. Considerando que esas actividades poseen una dimensión autónoma (lo que no quiere decir independiente) de las determinaciones sociales de género, clase, etnia, etc., destaco como eje de esta sistematización aquellas características relacionadas a la singularidad formativa, o al "quehacer creador", que la "danza", el "juego", la "lucha" y la "gimnasia" tienen o pueden llegar a tener para los sujetos que enseñan y aprenden tales actividades en la escuela.
*Universidade Federal de Santa Catarina. Florianópolis, SC, Brasil. E-mail: carolina_picchetti@ hotmail.com

Recebido em: 12-10-2017 Aprovado em: 29-05-2018

$\mathrm{DOI}$ http://dx.doi.org/10.22456/1982-8918.77157 (c) (1) (8) Licence 


\section{INTRODUÇÃO}

Apresento neste ensaio uma conceituação sobre os objetos de ensino da Educação Física a partir de uma compreensão histórico-cultural das práticas corporais. Desenvolvo essa proposição a partir do conceito de "cultura corporal" delineado pela perspectiva críticosuperadora da Educação Física (SOARES, 1992; TAFFAREL; ESCOBAR, 2009).

O pressuposto presente nessa perspectiva é que as atividades da cultura corporal são formas particulares da prática social, sintetizando determinadas necessidades, motivos e objetivos histórica e coletivamente produzidos. A análise dessas atividades, buscando sistematizar o conteúdo específico das relações sociais que as constituem, representa a principal ação metodológica para a proposição sobre os objetos de ensino da Educação Física.

Duas perguntas gerais orientam esse debate: em uma perspectiva cultural da Educação Física temos clareza sobre o que ensinamos quando dizemos que tematizamos o jogo, a dança, a luta, a ginástica etc.? Como esses conteúdos da Educação Física podem se articular a um projeto pedagógico "humanizador" ou "emancipador" do sujeito?

Inicio o ensaio problematizando o sentido pedagógico e didático de nos dedicarmos a uma investigação sobre os "objetos de ensino" no campo da Educação Física. Em seguida, apresento algumas questões metodológicas e alguns princípios teóricos que fundamentam a análise dos significados das atividades da cultura corporal em uma perspectiva históricocultural da formação humana. Parte-se da compreensão de que as "significações objetivas" sintetizam representações ou ideias produzidas pela consciência social em relação "ao lúdico, ao artístico, ao agonístico, ao estético etc." (SOARES, 1992, p.62). Esses princípios procuram ser exemplificados a partir da análise do processo de proposição dos significados da dança, 0 que nos permite discutir, então, alguns dos desdobramentos pedagógicos que as investigações sobre os objetos de ensino da Educação Física podem trazer para a prática pedagógica do professor de Educação Física Escolar.

\section{PROBLEMATIZAÇÕES INICIAIS SOBRE A INVESTIGAÇÃO DOS OBJETOS DE ENSINO DA EDUCAÇÃO FÍSICA}

É pertinente ainda formularmos perguntas como "o que ensinamos em Educação Física Escolar?". Uma resposta a essa questão precisa considerar os motivos para a elaboração da própria pergunta. Qual o produto visualizado ao fazermos tal pergunta? Uma lista de conteúdos? Uma proposta curricular que englobe os diferentes segmentos de ensino? Uma conceituação epistemológica sobre o objeto da área? Uma orientação didática para a prática docente?

Do ponto de vista da prática do professor de Educação Física essas diferentes orientações compõem, invariavelmente, um quadro geral de razões para seu engajamento na busca de uma resposta concreta à questão sobre "o que ensinamos" em Educação Física. A atividade docente coloca continuamente para o professor a necessidade de pensar, propor, organizar e avaliar os conteúdos a serem ensinados e aprendidos na escola, o que faz com que a pergunta "o que se ensina em Educação Física?" siga sendo pertinente para a prática desses sujeitos.

Do ponto de vista das pesquisas em Educação Física Escolar, contudo, a pertinência de seguirmos propondo essas investigações encontra sua justificativa na medida em que a 
problemática sobre a determinação dos "conteúdos de ensino" seja desenvolvida a partir da explicitação do sistema teórico que fundamenta uma determinada proposição sobre os objetos de ensino da área.

Diferentes posições teóricas sobre aquilo que a Educação Física é e/ou pode vir a ser levam-nos a diferentes compreensões sobre os seus objetos de ensino. Ainda que se utilize uma mesma expressão semântica, caso do termo "cultura corporal", podemos encontrar perspectivas teóricas distintas subsidiando o trabalho pedagógico (BRACHT, 1999), o que reforça a necessidade de explicitarmos quais são os princípios teórico-metodológicos que fundamentam nossas investigações sobre "o que ensinamos em Educação Física". Para o debate sobre uma Educação Física "cultural", assumo, neste ensaio, uma perspectiva históricocultural da cultura corporal.

As reflexões que proponho neste ensaio partem da compreensão de que a atividade pedagógica da Educação Física vincula-se a uma "ciência da ação" (GAMBOA, 2007): a ação pedagógica. Como tal, cabem às investigações no campo da Educação Física a tarefa primária e o compromisso político de produzir conhecimentos sobre os processos de ensino e de aprendizagem.

Essa defesa torna-se ainda mais relevante quando se considera junto com Antunes et al. (2005) e Siedentop (2002) que muitos dos trabalhos acadêmicos que se propõem a discutir a dimensão educativa da Educação Física não se inserem em um debate propriamente pedagógico. Mesmo nas pesquisas que abordam explicitamente a temática escolar "[...] 0 processo de ensino-aprendizagem, que deveria ser alvo principal das investigações, não é tema prioritário" (ANTUNES et al., 2005 p. 183). No cenário internacional, Siedentop (2002) avalia que há um crescente afastamento da área em relação ao estudo de seus "conteúdos específicos" (para ele, o jogo, a dança, a luta, a ginástica, o esporte). Na medida em que nos afastamos do estudo e ensino desses "conteúdos específicos" acabamos eliminando "a possibilidade de desenvolver um corpo de conhecimentos pedagógicos significativos para 0 ensino da Educação Física" (SIEDENTOP, 2002. p. 368, tradução nossa).

Diante dessas considerações iniciais, podemos perguntar: quais os critérios pedagógicos utilizados para se propor um significado (ou conjunto de significações) como central para a organização do ensino da dança, do jogo, da luta etc.? Quais relações destacamos nesses fenômenos para seu ensino e por que as destacamos? Enfrentam-se, aqui, questões epistemológicas concretas sobre a natureza das atividades da cultura corporal, sobre o que converte um fenômeno qualquer (por exemplo, a dança) em um objeto de ensino da Educação Física. Uma vez que essas posições orientam o processo de seleção e organização dos conteúdos de ensino para a área, discutir tais posições torna-se relevante para as investigações sobre o que ensinamos em Educação Física Escolar.

\section{CONSIDERAÇÕES METODOLÓGICAS PARA A ANÁLISE DOS SIGNIFICADOS DAS ATIVIDADES DA CULTURA CORPORAL}

Para nos inserirmos em um debate propriamente pedagógico sobre os objetos de ensino da Educação Física, consideramos relevante apresentar o modo de análise a partir do qual identificamos e sistematizamos os significados das atividades da cultura corporal. Partindo 
dos fundamentos teóricos do materialismo histórico e dialético como método de investigação (MARX; ENGELS 2007; KOPNIN, 1978;), destacamos duas ações metodológicas.

A primeira ação metodológica refere-se à análise de "episódios históricos" sobre as práticas corporais, de modo a identificar em determinados fatos ou situações da história humana elementos pertinentes para a discussão sobre o processo de constituição e desenvolvimento dos significados das atividades da cultura corporal. A segunda ação metodológica referese à análise dos conhecimentos pedagógicos produzidos sobre o jogo, a dança, a luta, a ginástica etc., de modo a sistematizar as possibilidades formativas específicas que essas atividades podem ter para o sujeito em um dado momento histórico e/ou em um dado contexto cultural.

O fundamento que sustenta essas duas ações metodológicas de investigação reside na compreensão de que os significados de uma atividade, sendo historicamente produzidos, transformam-se ao longo das épocas históricas e/ou dos grupos sociais nos quais emergem. Como argumenta Allen Guttmann (1978), essa transformação dos significados ocorre porque os conteúdos de uma atividade passam a ocupar posições diferentes na prática social e, assim, uma determinada atividade pode concentrar-se "em seus próprios elementos essenciais" (GUTTMANN, 1978, p.23).

A proposição de quais sejam esses "elementos essenciais" ou significações centrais das atividades da cultura corporal decorre, então, de um entrelaçamento entre o "lógico e 0 histórico" (KOPNIN, 1978), como unidade entre a história do fenômeno e a história dos conhecimentos produzidos sobre esse fenômeno. Esse quadro metodológico fundamenta, então, o modo como nos inserimos no processo de proposição sobre os objetos de ensino da Educação Física, dialogando tanto com autores que se dedicaram a estudar "episódios históricos" relacionados às práticas corporais (por exemplo: Caminada (1999) e Bourcier (2001) na dança; Dunning (1999), Franco Jr (2007) e Guttmann (1978) no Jogo Coletivo e no Esporte) quanto com autores que se dedicaram a sistematizar os conhecimentos pedagógicos específicos de cada uma dessas práticas (por exemplo: Humphrey (1962), Laban (1978) e Marques (2003) na dança; Mahlo ([1980]); Bayer (1994) e Garganta (1994) no Jogo Coletivo; Ramírez (1997), Kozub; Kozub (2004) e Gomes et al. (2010), na luta).

É a partir desse sistema teórico-metodológico que nos colocamos no processo de proposição dos objetos de ensino da Educação Física. Para o professor que atua na escola, inserir-se nesse debate faz-se relevante na medida em que contribui para revelar o processo de produção de significados que foram (e continuam a ser) materializados nos diversos exemplares da cultura corporal.

\section{ALGUNS FUNDAMENTOS HISTÓRICO-CULTURAIS PARA UMA CONCEITUAÇÃO SOBRE OS OBJETOS DE ENSINO DA EDUCAÇÃO FÍSICA}

A compreensão de que os objetos de ensino da Educação Física representam uma sistematização dos significados das atividades da cultura corporal fundamenta-se em um entendimento histórico-cultural sobre a "atividade" humana (DAVIDOV, 1988; LEONTIEV 1983; MARX; ENGELS, 2007). Uma "atividade" caracteriza-se fundamentalmente pelo seu objeto, que sintetiza os problemas fundamentais com os quais os sujeitos precisam agir 
para reconstituírem criadoramente a experiência humana que foi objetivada em tal atividade. O objeto da atividade direciona, assim, o conteúdo geral das ações dos sujeitos em seus processos de apropriação de uma dada atividade. No Quadro 1 sintetizo minha compreensão sobre alguns pressupostos histórico-culturais que fundamentam uma investigação sobre os objetos de ensino da Educação Física.

Quadro 1 - Fundamentos histórico-culturais para uma conceituação sobre os objetos de ensino da Educação Física.

1. Uma atividade é composta por um conjunto de ações historicamente desenvolvidas na prática social.

2. O objeto de uma atividade sintetiza o conteúdo central da ação dos sujeitos em sua atividade prática no mundo.

3. As ações de uma atividade relacionam-se aos problemas, objetivos e instrumentos com os quais os sujeitos devem se engajar para reconstituírem tal atividade para si.

4. Uma atividade é simultaneamente atividade objetivada pela prática social e atividade a ser apropriada pelos sujeitos singulares que atuam nessa mesma prática social.

5. Conhecimento é síntese entre a atividade prática dos sujeitos no mundo (o movimento histórico) e a atividade teórica desses sujeitos para compreender e sistematizar a sua atuação nesse mundo (o movimento lógico).

Fonte: elaboração da autora

O objeto de uma atividade sintetiza os problemas fundamentais em relação aos quais as ações dos sujeitos devem estar orientadas [item 2]. Esses problemas são qualificados como "fundamentais" ou centrais porque demonstraram ser determinantes para o surgimento $\mathrm{e}$ desenvolvimento de uma dada atividade ao mesmo tempo em que se apresentam, ainda hoje, como determinantes para a atuação dos sujeitos na singularidade dessa mesma atividade.

O objeto de uma atividade pode ser sistematizado logicamente sob a forma de "significados" (LEONTIEV, 1983): como síntese teórica das relações entre necessidades, motivos, objetivos e instrumentos que foram historicamente desenvolvidos em uma dada prática social [itens 1 e 3]. Nesse sentido, o conhecimento é compreendido como unidade entre 0 desenvolvimento dos fenômenos e o desenvolvimento dos processos de compreensão desses mesmos fenômenos [item 5], unidade essa dada na e pela prática social (KOPNIN, 1978).

Conhecimento e aprendizagem são concebidos, assim, na dinâmica real dos sujeitos em atividade: a atividade humana que foi historicamente objetivada no mundo e a atividade singular dos sujeitos que buscam reconstituir essa atividade para si [item 4]. Por conta dessa unidade a atividade possui ao mesmo tempo uma dimensão de permanência e de transformação, nas quais os sujeitos criam e recriam o mundo ao mesmo tempo em que criam a si mesmos como individualidades (LAVE, 1996; MOURA; SFORNI; ARAÚJO, 2011).

Desses pressupostos apresentados no Quadro 1 desdobra-se a compreensão de que cabe à Educação Física estudar as atividades da cultura corporal a fim de descobrir respostas sobre quais são as ações necessárias para que os sujeitos joguem, dancem, lutem, brinquem etc. A qualidade dessas ações é dada pela relação entre as capacidades humano-genéricas historicamente objetivadas em cada uma dessas atividades e o projeto de sociedade e de homem que buscamos concretizar e que pode (no sentido de potencialidade) se manifestar nessas formas particulares da atividade humana. No Quadro 2 descrevo alguns dos pressupostos que organizam o modo como me insiro nas investigações sobre "o que ensinamos em Educação Física". 
Quadro 2 - Pressupostos para a investigação dos objetos de ensino em Educação Física.
1. A Educação Física é uma área de conhecimento que compõe parte integrante do projeto político pedagógico da escola.
2. A organização da Atividade Pedagógica da Educação Física requer uma sistematização didática de seus conteúdos de ensino na direção da formação humano-genérica dos sujeitos.
3. Em uma perspectiva "cultural" pode-se considerar que o fenômeno com o qual a Educação Física lida são os diversos exemplares das atividades da cultura corporal (as diversas formas de brincadeira, ginástica, dança, jogo, luta, circo etc.).
4. As atividades da cultura corporal são uma forma particular da prática social, sintetizando determinados significados que foram historicamente produzidos pelos sujeitos em relação às "ações corporais lúdicas". 5. A identificação e sistematização dos significados específicos das atividades da cultura corporal a partir de uma análise histórica das práticas corporais constitui-se na ação metodológica central para a proposição dos objetos de ensino da Educação Física.

Fonte: elaboração da autora

Embora os conteúdos apresentados no Quadro 2 estejam relacionados à perspectiva teórica que assumo em minhas investigações, pode-se considerar que há neles algumas problemáticas gerais que precisam ser consideradas em quaisquer investigações sobre "0 que ensinamos" em Educação Física. Por exemplo, a definição inicial do fenômeno com o qual a Educação Física lida (itens 3 e 4); o papel da Educação Física no contexto do ensino escolar (itens 1 e 2); as ações metodológicas para se propor os objetos de ensino da área (item 5). Assim, o que pretendo destacar com a apresentação desse quadro é a necessidade de explicitarmos os pressupostos a partir dos quais nos inserirmos nas investigações sobre "o que ensinamos em Educação Física".

Para discutir concretamente essa conceituação sobre os objetos de ensino da Educação Física apresento, a seguir, uma análise do processo de identificação e proposição dos significados de uma das atividades da cultura corporal (a dança), o que nos permitirá destacar alguns dos desdobramentos pedagógicos desse tipo de análise para a prática do professor de Educação Física.

\section{OS SIGNIFICADOS DAS ATIVIDADES DA CULTURA CORPORAL E OS OBJETOS DE ENSINO DA EDUCAÇÃO FÍSICA: A DANÇA COMO UM EXEMPLAR PARA A ANÁLISE}

Para analisarmos os possíveis significados da dança como exemplar da cultura corporal e, assim, discutir uma proposição sobre os objetos de ensino da Educação Física, consideremos a seguinte questão inicial: quais são os critérios pedagógicos para a escolha de um determinado estilo de dança (ex.: danças folclóricas, cantigas de roda, hip hop) e/ou de um determinado aspecto da dança (ex.: coordenação motora, flexibilidade, criatividade, promoção da saúde, gênero, passos e coreografias) como conteúdo para seu ensino na Educação Física?

A primeira discussão que podemos destacar a partir dessa pergunta refere-se à problematização sobre propostas curriculares que apresentam os conteúdos de ensino da cultura corporal em uma dimensão estritamente descritiva (i.e., a apresentação de uma lista de exemplares de danças). A questão é que, seja qual for essa lista, é preciso explicitar os critérios pedagógicos que permitiram selecionar e organizar os diferentes conhecimentos a serem ensinados e aprendidos em um trabalho pedagógico com a dança na escola. $O$ que exatamente o professor organiza ou tematiza ao ensinar esse ou aquele exemplar da dança? 
O que faz a coordenação motora, o debate sobre gênero ou mesmo a coreografia ser um conteúdo específicos da dança no contexto da prática pedagógica da Educação Física?

Essa problemática é também reconhecida por alguns autores que analisaram propostas curriculares para o ensino de dança no campo da Educação Física Escolar (ver, por exemplo, os trabalhos de Buogo e Lara (2011), Diniz e Darido (2015) e Rodrigues (2016)).

Uma proposição sobre o objeto de ensino (da dança) no campo da prática pedagógica da Educação Física deve sistematizar uma explicação sobre aquilo que a dança é (como fenômeno histórico e cultural) e sobre aquilo que ela pode vir a ser para a formação dos sujeitos que nela se engajem na dinâmica de ensino e aprendizagem que se dá na escola. Para explicitar essa relação entre o "ser" e o "vir a ser" de uma atividade da cultura corporal é preciso identificar o significado (ou conjunto de significados) historicamente produzido pela prática social.

Um estudo sobre "o significado da dança" tendo em vista sistematizar orientações para a prática pedagógica da Educação Física deve reconhecer, incialmente, a existência de uma multiplicidade de significados compondo esse fenômeno: religiosos, artísticos, recreativos, educativos, midiáticos, para a saúde etc. (ver por exemplo, Strazzacappa (2001)).

Essa diversidade de significações pode ser exemplificada em alguns artigos de revisão sobre o ensino da dança no campo da Educação Física. Santiago e Franco (2015), por exemplo, propõem cinco temáticas para agrupar os diferentes enfoques presentes nos 53 trabalhos que analisaram: dança e mídia; dança e arte; dança, gênero, sexualidade, raça e etnia; dança e práticas corporais; dança e educação. Muglia-Rodrigues e Correia (2013) propõem outras cinco classificações ${ }^{1}$ para agrupar os 67 artigos que analisaram: estudos socioculturais do movimento humano; pedagogia do movimento humano; biodinâmica do movimento humano; adaptação do movimento humano; comportamento motor.

Dessas diferentes significações ou conceituações para a dança podem decorrer diferentes proposições sobre qual seria o objeto de ensino da Educação Física ao trabalhar com tal atividade. Brasileiro (2003) e Kleinubing e Saraiva (2009) destacam em suas análises três concepções recorrentes que orientam a prática pedagógica do professor de Educação Física: a) a dança como instrumento de sociabilização (KLEINUBING; SARAIVA 2009); b) a dança como instrumento para o desenvolvimento motor (BRASILEIRO, 2003; KLEINUBING; SARAIVA 2009); e c) a dança como expressão cultural de um povo (BRASILEIRO, 2003).

Diante dessas considerações iniciais sobre as diversas possibilidades de significações para a dança, uma questão que nos parece central de ser respondida refere-se à determinação dos critérios pedagógicos utilizados para se propor um significado (ou conjunto de significações) como central para a organização do ensino da dança.

Em uma perspectiva cultural da Educação Física pode-se afirmar que a dança (assim como qualquer atividade da cultura corporal) constitui-se como expressão de diferentes relações sociais, diferentes culturas e etnias, marcadas por determinados modos de produção de uma época. Essa condição histórico-cultural da dança pode nos levar a uma posição pedagógica na qual o seu ensino constitua-se prioritariamente em um meio para problematizar tais relações: a dança seria um meio para estudar a sociedade, uma época, uma identidade cultural etc. Mas a defesa inicial que faço é que o ensino da dança pode ser mais do que isso no trabalho pedagógico da Educação Física.

1 Os autores utilizam uma perspectiva cinesiológica da Educação Física para essa classificação. 
As atividades da cultura corporal possuem uma especificidade formativa em relação à "ação criadora"" dos sujeitos que dançam, jogam, lutam etc. que "[...] ser negado delas ou não ser capaz de realizá-las ou recordá-las seria afastar-se do sujeito que elas contribuíram para que eu me tornasse" (ARNOLD, 1979, p. 26, tradução nossa).

O basquete me permitiu descobrir o sentimento verdadeiro que acompanha a busca da perfeição. Eu posso apreciar agora o que um músico experimenta enquanto se esforça para alcançar uma perfeita combinação de notas, ou um escritor para alcançar uma perfeita disposição das palavras (RALKAVSKY, M. apud ARNOLD, 1979, p. 50, tradução nossa).

Assim, o ensino das atividades da cultura corporal pode ter por finalidade última trabalhar com esse potencial formativo que foi historicamente materializado nessa esfera da vida e que pode ser sintetizado nos significados específicos das atividades da cultura corporal. Esses significados específicos explicitam a unidade entre os problemas fundamentais com os quais os sujeitos precisam se engajar e os meios historicamente elaborados para resolver tais problemas na direção de uma atuação criadora nas atividades de dança, jogo, luta, ginástica etc. Temos, aqui, o critério pedagógico central para a determinação dos objetos de ensino da Educação Física em uma perspectiva histórico-cultural.

Esse critério remete-nos a analisar as atividades da cultura corporal não apenas como determinadas pelas condições sociais das quais fazem parte (de gênero, classe, etnia etc.), mas fundamentalmente como determinantes de relações sociais relacionadas à capacidade criadora do sujeito. Compreende-se, então, que os princípios educativos relacionados a uma educação crítica ou emancipatória, problematizando a prática social em direção a uma leitura crítica da realidade por parte de educandos e educadores (SAVIANI, 2005; SOARES, 1992), não encontram legitimidade no campo da Educação Física somente ou prioritariamente quando se tematizam "questões sociais" a partir das práticas corporais. Embora tematizar questões de gênero, desigualdade, etnia, injustiças, valores, padrões estéticos etc. seja parte indissociável dos conteúdos de ensino das atividades da cultura corporal, elas não são os objetos de ensino da Educação Física.

A defesa metodológica e pedagógica que faço refere-se à compreensão de que é a partir do engajamento do sujeito na especificidade do "fazer em dança, jogo, luta etc." (no agir com o conteúdo específico dessas atividades) que a prática pedagógica organizará a relação desse sujeito com as muitas e múltiplas relações humanas que estão encarnadas nelas. Reconhecer a dimensão autônoma dessas atividades, a sua positividade e o seu potencial de autocriação para os sujeitos que nelas se engajam passa a ser condição primária para analisálas em sua dimensão de atividade determinada por essas mesmas relações sociais.

No campo da dança encontramos semelhante posição nos trabalhos de autores como Laban (1978), Humphrey (1962) e Marques (2003). Sem desconsiderar o pressuposto da determinação social da dança, esses autores a analisam fundamentalmente como uma atividade autônoma, cujo significado específico pode contribuir para a formação de um sujeito criador de si e do mundo.

O engajamento dos sujeitos na especificidade da atividade de dança requer "que os indivíduos criem formas do se movimentar (na verdade, novas combinações" (KUNZ, 1994,

2 É uma "ação criadora" aquela que expressa uma relação consciente e voluntária do sujeito com uma determinada atividade: 0 sujeito reconhece a si mesmo como sujeito criador, capaz de transformar aquilo que a atividade é naquilo que ela pode vir a ser. "É precisamente a atividade criadora do homem a que faz dele um ser projetado ao futuro, um ser que cria e transforma seu presente" (VIGOTSKY, 2004, p. 6, tradução nossa). 
p.167, grifos da autora) ou que se envolvam com o aspecto coreológico da dança (KLEINUBING; SARAIVA; MELO, 2011; MARQUES, 2003). Esse significado - que expressa o conteúdo direto da ação do sujeito que dança (o objeto dessa atividade) - pode ser sintetizado como sendo a ação de "criação de uma imagem artística a partir da composição e decomposição dos movimentos corporais no tempo, espaço, força e fluência" (NASCIMENTO, 2014; LABAN, 1978).

Esse seria, então, o conteúdo fundamental a ser estudado e tematizado pela Educação Física, a significação central para o estudo-ensino da dança pela Educação Física (Escolar). Dizemos "central" porque é justamente a partir dessa significação, que coloca a ação criadora do sujeito que dança no centro do processo educativo (BUOGO e LARA, 2011; KUNZ, 1994; MARQUES, 2003; SOARES; SARAIVA, 1999), que passamos a estabelecer relações com as demais significações que compõem o fenômeno dança. Entende-se que "o corpo que dança e o corpo na dança tornam-se fonte de um conhecimento sistematizado e transformador" (MARQUES, 2003, p. 25).

O desafio do trabalho pedagógico com essa significação central da dança está em compreender e tratar esse problema fundamental de "criação de uma imagem com as formas dos movimentos corporais" como um problema permanente para o engajamento do sujeito na especificidade dessa atividade: o conteúdo efetivo de ensino e de aprendizagem que permeará as diferentes ações pedagógicas e tematizações a partir da dança ${ }^{3}$.

Essa compreensão da dança nos dá determinadas possibilidades para nossa atuação pedagógica no campo da Educação Física Escolar. Passamos a ver, em primeiro plano, o problema central com o qual os sujeitos devem se engajar para reproduzirem criadoramente essa atividade para si. É a partir dessa referência que organizamos o lugar e o papel dos muitos "conteúdos" atribuídos à dança, por exemplo, os seus diversos exemplares, a coordenação e 0 ritmo, as relações raciais e de gênero etc.

Sem essa sistematização dos significados centrais ou específicos das atividades da cultura corporal, é provável que passemos a tratar, como objeto de ensino da Educação Física, significações de outras atividades e não especificamente aquelas da dança, do jogo, da luta, da ginástica etc. A argumentação é que um mesmo fenômeno (por exemplo, a dança), ao ser analisado por um historiador, por um físico ou por um professor de Educação Física, resultará na sistematização de significados distintos como centro de seus sistemas conceituais, porque distintas são as atividades com as quais cada um desses campos trabalha.

Podemos reafirmar, então, que uma proposição sobre os objetos de ensino da Educação Física depende, fundamentalmente, da análise que fazemos sobre as atividades da cultura corporal. O critério pedagógico geral que destacamos para essa análise refere-se à sistematização daqueles significados que explicitem a particularidade formativa de cada uma das atividades da "cultura corporal", sintetizando os problemas fundamentais com os quais os sujeitos devem se engajar na dança, no jogo, na luta, na ginástica etc. para reconstituírem para si as ações criadoras que foram historicamente objetivadas em tais atividades. Esses significados passam a ser o ponto de partida (ou o núcleo) a partir do qual podemos desdobrar um sistema de significações que fazem parte (ou podem fazer parte) do trabalho pedagógico da Educação Física.

3 Nos limites deste ensaio não apresentaremos uma explicação do sistema conceitual que compõe esse significado destacado para a dança. Para tal, ver os autores referenciados: Laban (1978); Marques (2003); Nascimento (2014). 
Retomando a concepção de Educação Física como uma "ciência da ação" (GAMBOA, 2007) e a condição do professor como "sujeito criador da atividade pedagógica" que, para tal, precisa conhecer e organizar pedagogicamente os significados das atividades da cultura corporal, compreende-se que uma proposição dos objetos de ensino da Educação Física não seja uma tarefa apenas dos pesquisadores, mas, também, uma ação indispensável da prática pedagógica do professor.

O trabalho pedagógico do professor lida permanentemente com a busca de respostas sobre: "o que pretendo ensinar ao trabalhar essa ou aquela manifestação corporal; por que pretendo ensinar isso para esse ou aquele grupo de sujeitos; como materializar didaticamente essa intencionalidade pedagógica". Ao tematizar as atividades da cultura corporal, o professor irá sempre se deparar com a necessidade de analisar uma prática corporal específica naquilo que ela é e naquilo que ela pode vir a ser para a formação dos seus alunos. Assim, uma proposição sobre os objetos de ensino da Educação Física apresenta-se para o professor como instrumento para seu trabalho de organização do ensino: estabelece uma referência a partir da qual se selecionam e organizam as múltiplas características que compõem cada uma das atividades da cultura corporal.

\section{CONSIDERAÇÕES FINAIS}

Neste trabalho defendi que uma proposição sobre os objetos de ensino da Educação Física implica, fundamentalmente, a explicitação dos critérios teórico-metodológicos a partir dos quais analisamos as atividades da cultura corporal e sistematizamos aqueles significados que ocuparão o centro das ações dos sujeitos que ensinam e aprendem o jogo, a dança, a luta etc. Procurei argumentar que, em uma perspectiva histórico-cultural - na qual a prática social é o pressuposto para a análise das atividades da cultura corporal -, esses significados referem-se àqueles conteúdos que permitem aos sujeitos se engajarem com as ações criadoras próprias dessa esfera da vida. Trata-se, assim, de problemas permanentes com os quais os sujeitos devem se engajar para lidarem com a especificidade do "fazer em" dança, jogo, ginástica, luta etc., "fazer" esse que se relaciona diretamente com as possibilidades do fazer-se sujeito por meio de tais atividades.

Defendi, também, que a proposição de um determinado significado como central reflete a posição de que esse conteúdo ocupa o centro de um sistema, no caso, a prática pedagógica da Educação Física. É a partir desse "centro" que se desdobram as muitas relações dos sujeitos com os fenômenos com os quais a Educação Física lida.

Essa perspectiva de análise que coloca como critério pedagógico para a determinação dos significados das atividades da cultura corporal a ação criadora dos sujeitos nas atividades de dança, jogo, luta e ginástica remete-nos a uma linha de investigação sobre a prática pedagógica da Educação Física fundamentada na perspectiva crítico-superadora. O foco das discussões esteve na problematização e argumentação sobre como nos engajamos nesse tipo de investigação. Buscou-se, com isso, justificar a pertinência de ainda elaborarmos pesquisas que busquem dar respostas à questão sobre "o que ensinamos em Educação Física" via análise das atividades que produziram e compõem o universo da "cultura corporal". Este é o desafio que segue para nossas investigações: conceituarmos quais são os significados específicos das atividades da "cultura corporal" e os desdobramentos pedagógicos de tal conceituação. 


\section{REFERÊNCIAS}

ANTUNES, Fabia Helena Chiorboli et al. Um retrato da pesquisa brasileira em Educação Física escolar: 1999-2003. Motriz, v.11, n 3, p. 179-184, set./dez. 2005.

ARNOLD, Peter. Meaning in movement, Sport and Physical Education. Londres: Heinemann, 1979.

BAYER, Claude. 0 ensino dos desportos colectivos. Lisboa: Dinalivro, 1994.

BOURCIER, Paul. História da dança no ocidente. São Paulo: Martins Fontes, 2001.

BRACHT, Valter. A constituição das teorias pedagógicas da educação física. Cadernos Cedes, v. 19, n. 48, p.69-88, ago. 1999.

BRASILEIRO, Lívia Tenório. O conteúdo "dança" em aulas de educação física: temos o que ensinar? Pensar a Prática, v.6, n.1, p. 45-58, jun/jul 2003.

BUOGO, Edmara Cristina Bonetti; LARA, Larissa Michelle. Análise da dança como conteúdo estruturante da educação física nas diretrizes curriculares da educação básica do Paraná.

Revista Brasileira de Ciências do Esporte, v.33, n.4, p.873-888, out./dez. 2011.

CAMINADA, Eliana. História da Dança: evolução cultural. Rio de Janeiro: Sprint, 1999.

DAVIDOV, Vasili V. La enseñanza escolar y el desarrollo psíquico: investigación teórica y experimental. Moscou: Progreso, 1988.

DINIZ, Irlla Karla dos Santos; DARIDO, Suraya Cristina. Análise do conteúdo dança nas propostas curriculares estaduais de educação física do Brasil. Revista da Educação Físical UEM, v. 26, n. 3, p. 353-365, set. 2015.

DUNNING, Eric. Sport matters: sociological studies of sport, violence, and civilization. London: Routledge, 1999

FRANCO JR. Hilário. A dança dos deuses, futebol, sociedade, cultura. São Paulo: Companhia das Letras, 2007.

GAMBOA, Sílvio Sánchez. Epistemologia da Educação Física: as inter-relações necessárias. Maceió: Editora UFAL, 2007.

GARGANTA, Julio. Para uma teoria dos jogos desportivos colectivos. In: GRAÇA, Amandio; OLIVEIRA, José O. 0 ensino dos jogos desportivos. Porto: Rainho \& Neves, 1994. p.11.25.

GOMES, Mariana Simões Pimentel et al. Ensino das lutas: dos princípios condicionais aos grupos situacionais. Movimento, v. 16, n. 2, p. 207-227, 2010.

GUTTMANN, Allen. From ritual to record: the nature of modern Sports. New York: Columbia University, 1978.

HUMPHREY, Doris. The art of making dance. New York: Grove, 1962.

KLEINUBING, Neusa Dendena; SARAIVA, Maria do Carmo. Educação Física Escolar e dança: percepções de professores no Ensino Fundamental. Movimento, v. 15, n. 4, p. 193-214, 2009. 
KLEINUBING, Neusa Dendena; SARAIVA, Maria do Carmo; MELO, Damiana Fernandes de. Saberes possíveis no processo de ensinar e aprender dança: revisitando bases epistemológicas. Conexões, v. 9, n. 2, p. 199-218, set. 2011.

KOPNIN, Pavel Vassílyevitch. A dialética como lógica e teoria do conhecimento. Rio de Janeiro: Civilização Brasileira, 1978.

KOZUB, Francis M.; KOZUB, Mary, L. Teaching combative sports through tactic. Journal of Physical Education, Recreation and Dance, v. 75, n.8, p.16-21, out. 2004.

KUNZ, Maria do Carmo Saraiva. Ensinando a dança através da improvisação. Motrivivência, v. 4, n. 5, p. 166-169, dez. 1994.

LABAN, Rudolf. Domínio do movimento. Rio de Janeiro: Summus, 1978.

LAVE Jean. The practice of learning. In: CHAIKLIN, Seth; LAVE Jean. Understanding practice: perspectives on activity and context. Cambridge: Cambridge University, 1996. p.3-34.

LEONTIEV, Alex N. Actividad, conciencia y personalidad. Havana: Pueblo y educación, 1983.

MAHLO, Friedrich. 0 acto táctico no jogo. Lisboa: Compendium, [1980].

MARQUES, Isabel. Dançando na escola. São Paulo: Cortez, 2003.

MARX, Karl; ENGELS, Friedrich. A ideologia alemã. São Paulo: Boitempo, 2007.

MOURA, Manoel Oriosvaldo de; SFORNI, Marta; ARAÚJO, Elaine Sampaio. Objetivação e apropriação de conhecimentos na atividade orientadora de ensino. Teoria e Prática da Educação, v 14, n. 1, p. 39-50, jan./abr. 2011.

MUGLIA-RODRIGUES, Barbara; CORREIA, Walter Roberto. Produção acadêmica sobre dança nos periódicos nacionais de Educação Física. Revista Brasileira de Educação Física e Esporte, v.27, n.1, p.91-99, mar. 2013.

NASCIMENTO, Carolina Picchetti. A atividade pedagógica da Educação Física, a proposição dos objetos de ensino e o desenvolvimento das atividades da cultura corporal. 2014. $293 \mathrm{f}$. Tese (Doutorado em Educação) - Programa de Pós-Graduação em Educação, Faculdade de Educação, Universidade de São Paulo, São Paulo, 2014.

RAMÍREZ, Fernando Amador. El análisis de la acción de lucha. In: RAMÍREZ, Fernando Amador. El Judô y las ciências de la educación física y el deporte. Vitoria - Gasteiz: Instituto Vasco de Educación Física,1997. p.51-70.

RODRIGUES, Anegleyce Teodoro. Base Nacional Comum Curricular para a área de linguagens e o componente curricular Educação Física. Motrivivência, v. 28, n. 48, p. 32-41, set. 2016.

SANTIAGO, Bruna Gomes; FRANCO, Neil. Dança na Revista Brasileira de Ciências do Esporte (1979-2014). Motrivivência, v. 27, n. 45, p. 189-208, set. 2015.

SAVIANI, Dermeval. Pedagogia Histórico-Crítica: primeiras aproximações. Campinas: Autores Associados, 2005.

SIEDENTOP, Daryl. Content Knowledge for Physical Education. Journal of teaching in physical education, v. 21, n.4, p. 368-377, jul. 2002. 
SOARES, Andressa Silveira; SARAIVA, Maria do Carmo. Fundamentos teórico-metodológicos para a dança na Educação Física. Motrivivência, n. 13, p.103-1999, jan. 1999.

SOARES, Carmen Lúcia et al. Metodologia do ensino da Educação Física. São Paulo: Cortez. 1992.

STRAZZACAPPA, Marcia. A educação e a fábrica de corpos: a dança na escola. Cadernos Cedes, v.21, n. 53, p.69-83, abril. 2001.

TAFFAREL, Celi Zülke; ESCOBAR, Micheli Ortega. Cultura Corporal e os dualismos necessários a ordem do Capital. Revista Eletrônica Rascunho Digital, 2009. Disponível em: <http://www. rascunhodigital.faced.ufba.br/ver.php?idtexto=277> . Acesso em: 11 out.2017.

VIGOTSKY, Lev Semionovich. Imaginación y creación en la edad infantil. Havana. Pueblo y Educación, 2004. 


\section{Agradecimentos:}

Agradeço ao Luiz Eduardo Pinto Basto Tourinho Dantas pela leitura crítica do texto e pelos permanentes debates sobre os objetos de ensino da Educação Física. Agradeço ao Ori (Manoel Oriosvaldo de Moura) pelas contribuições sobre a exposição das ideias no texto e pelas permanentes discussões sobre a "atividade pedagógica". 